\title{
Os Gabinetes Civis na Administração Pública Federal
}

(Contribuição ao estudo da Reforma Administrativa)

Walter Ferri

Economista; Chefe do Gabinete do Ministro do Interior

\section{INTRODUÇÃO}

As atribuições, a organização interna e as qualificações requeridas para os recursos humanos têm sido, relativamente, pouco estudadas e analisadas no que diz respeito aos Gabinetes Civis na Administração Pública Federal. Por outro lado, verifica-se interesse constante sobre informações a esse respeito, bem como a necessidade, do ponto de vista administrativo, de uniformizar estas unidades, a fim de ajustá-las à concepção sistêmica, implantada pelo Decreto-lei $n .^{\circ} 200$.

Estes motivos levaram o autor a preparar o presente trabalho, que é de sua inteira responsabilidade, independentemente do Orgão em que trabalha.

\section{CONCEITOS BÁSICOS}

Os textos básicos do Decreto-lei $n .^{\circ} 200$ relacionados com os Gabinetes Civis são os seguintes:

"Art. 29 - Em cada Ministério Civil, além dos Órgãos Centrais de que trata o Art. 22, o Ministro de Estado disporá de assistência direta e imediata de: 
I - Gabinete;

II - Consultor Jurídico, exceto no Ministério da Fazenda;

III - Divisão de Segurança e Informações.

$\S 1 .^{\circ}-\mathrm{O}$ Gabinete assiste o Ministro de Estado em sua representação política e social, e incumbe-se das relações públicas, encarregando-se do preparo e despacho do expediente pessoal do Ministro"...

"Art. 33 - Ao Gabinete Civil incumbe:

I - Assistir direta e imediatamente o Presidente da República no desempenho de suas atribuições $e$, em especial, nos assuntos referentes à administração civil.

II - Promover a divulgação de atos e atividades governamentais.

III - Acompanhar a tramitação de projetos de lei no Congresso Nacional e Coordenar a colaboração dos Ministérios e demais Órgãos da Administração, no que respeita aos projetos de lei submetidos à sanção presidencial".

A fim de melhor esclarecer os conceitos básicos, reproduz-se o Art. 22, citado no Art. 29:

"Art. 22 - Haverá na estrutura de cada Ministério Civil os seguintes Órgãos Centrais:

1 - Órgãos Centrais de Planejamento, Coordenação e Controle Financeiro.

II - Órgãos Centrais de Direção Superior".

Conforme explicita o Art. 23, os Órgãos a que se refere 0 item I são as Secretarias-Gerais e as Inspetorias de Finanças. Os Órgãos indicados no item II são; geralmente, denominados
Departamentos de Administração.

R. Serv. Públ., Brasília, 108 (2): mai./ago. 1973 


\section{COMPARAÇÃO DE ATRIBUIÇÕES ENTRE O GABINETE CIVIL DA PRESIDENCIA E OS GABINETES MINISTERIAIS}

A partir dos conceitos básicos, pode-se estabelecer o seguinte quadro comparativo de atribuições:

\section{Gabinete Civil da Presidência}

\section{Gabinetes Ministeriais}

1. Assistir, direta e imediatamente, o Presidente da República no desempenho de suas atribuições.

2. Idem, em especial, nos assuntos referentes à administração civil.

3. Promover a divulgação de atos e atividades governamentais.

4. Acompanhar a tramitação de projetos de lei no Congresso Nacional.

5.

6.

7. -

1. -

2. -

3. -

4. -

5. Assistir direta e imediatamente o Ministro de Estado em sua representação política e social.

6. Incumbir-se das relações públicas.

7. Preparar o despacho do expediente pessoal do Ministro.

Verifica-se, neste confronto, diferenças nas atribuições, apesar do nome Gabinete. As atribuições do item 1 do Gabinete Civil da Presidência, nos Ministérios Civis, são desempenhadas pela Secretaria-Geral, sendo o Secretário-Geral o substituto eventual do Ministro de Estado. 0 item 2 das atribuições do Gabinete Civil da Presidência, nos Ministérios Civis, são desempenhadas pelos Órgãos Centrais de Direção Superior. O 
item 4, apesar de não estar explicitado nos Ministérios Civis, é desempenhado pelos Gabinetes através das Assessorias Parlamentares. Finalmente, o item 6, que é atribuição dos Gabinetes dos Ministérios Civis, na Presidência da República, é atribuição da Assessoria Especial de Relações Públicas (AERP), diretamente subordinada ao Presidente.

\section{FUNÇÕES ADMINISTRATIVAS E CONCEITOS BÁSICOS DE ADMINISTRAÇÃO SISTEMMICA}

Partindo, ainda, dos conceitos básicos e compreendendo a administração sistêmica como sendo composto de um Órgão Central do qual emanam as orientações técnicas às quais se vinculam as Unidades Ministeriais, neste aspecto que, por sua vez, estão subordinadas administrativa e funcionalmente ao $\mathrm{Mi}$ nistro de Estado, pode-se apresentar a atual Administração Pública Federal, através do seguinte diagrama: 


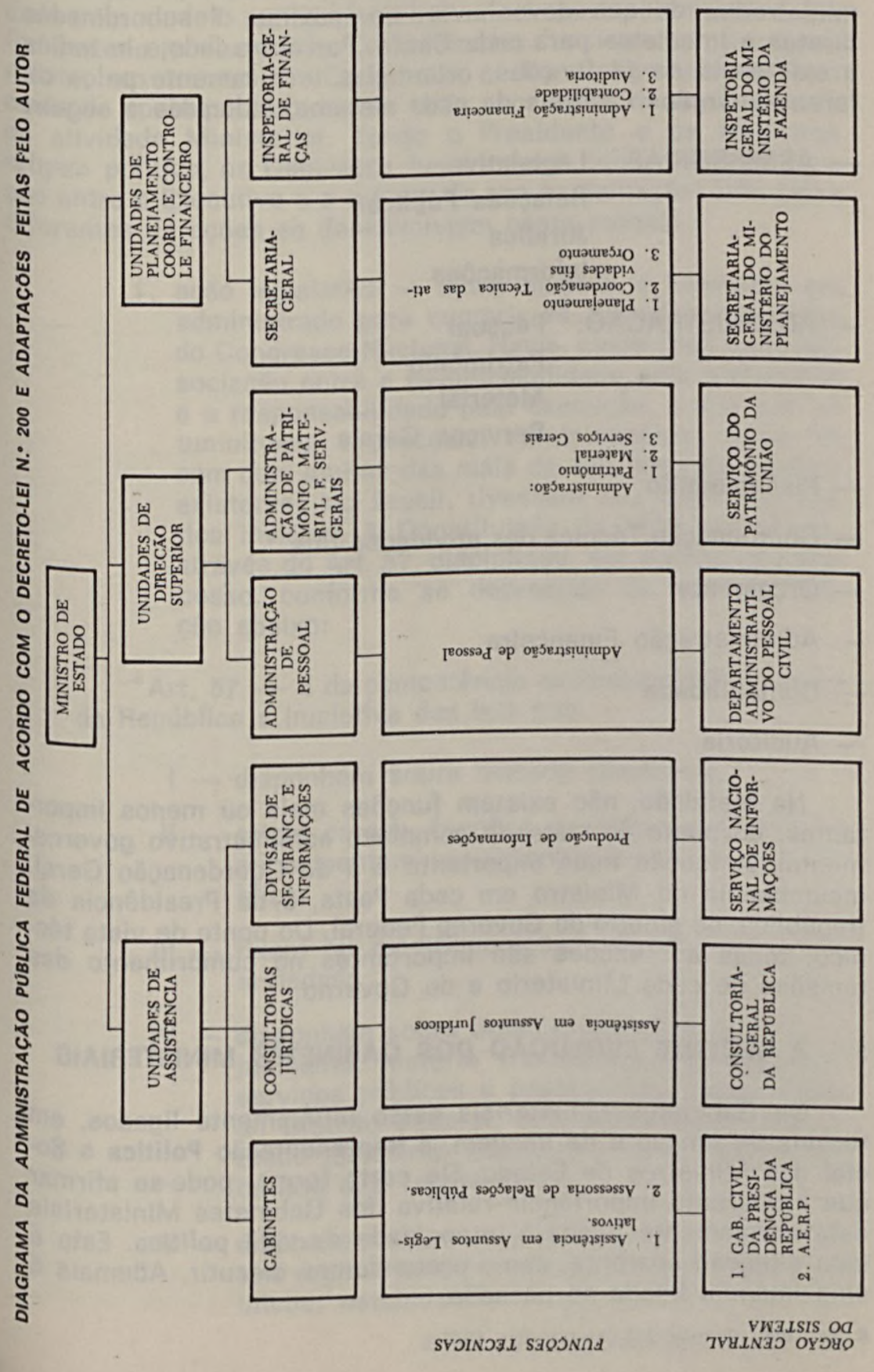


Este diagrama apresenta-se coerente com o princípio administrativo de que deve haver, no máximo, 7 subordinados diretos e imediatos para cada Chefe. Por outro lado, ele indica a existência de 14 funções, orientadas tecnicamente pelos diferentes Órgãos Centrais de cada sistema, indicadas a seguir:

- ASSESSORIAS: Legislativa

Relações Públicas
Jurídica
Informações

- ADMINISTRAÇÃO: Pessoal

Patrimônio

Material

Serviços Gerais

- Planejamento

- Coordenação Técnica das atividades fins

- Orçamento

- Administração Financeira.

- Contabilidade

- Auditoria

Na realidade, não existem funções mais ou menos importantes, do ponto de vista do complexo administrativo governamental. A função mais importante é a de Coordenação Geral, incumbência do Ministro em cada Pasta, e da Presidência da República, no âmbito do Governo Federal. Do ponto de vista técnico, todas as funções são importantes no cumprimento das missões de cada Ministério e do Governo.

\section{A RECENTE EVOLUÇÃO DOS GABINETES MINISTERIAIS}

Os Gabinetes Ministeriais estão intimamente ligados, em termos de função e de imagem, à Representação Política e So-
cial dos Ministros de Estado. De certa forma, pode-se afirmar
que a aparente importâncio que a aparente importância relativa dos Gabinetes Ministeriais umá intimamente ligada à intensidade da vida política. Esta é uma situação aparente, como pretendemos discutir. Ademais é uma imagem ligada ao passado. 
$\mathrm{Na}$ fase em que a administração pública federal era comandada pelo modelo político-legislativo, a importância relativa dos Gabinetes era destacada. Os Gabinetes funcionavam, principalmente, em termos do Congresso e dos Congressistas, bem como do apoio político que se fazia necessário no cumprimento da atividade Ministerial. Tendo o Presidente e os Ministros origem política, os Gabinetes funcionavam como meio de ligação entre o Executivo e a origem de sua sustentação. Três tipos diferentes de ações se desenvolviam neste modelo.

1. ação legislativa - neste modelo, o Executivo era administrado para cumprir as decisões emanadas do Congresso Nacional. Havia, neste caso, uma dissociação entre a responsabilidade pela proposição e a responsabilidade pela execução, o que não só tumultuava o processo administrativo, como fez com que, muitas das mais de 100.000 leis federais existentes no Brasil, tivessem sua execução prática inviável. A Constituição de 1969, entretanto, através do Art. 57, disciplinou, em muito, este processo, conforme se depreende da sua reprodução abaixo:

"Art. 57 - É da competência exclusiva do Presidente da República a iniciativa das leis que:

1 - disponham sobre matéria financeira;

II - criem cargos, funções ou empregos públicos ou aumentem vencimentos ou a despesa pública;

III - fixem ou modifiquem os efetivos das forças armadas;

IV - disponham sobre organização administrativa e judiciária, matéria tributária e orçamentária, serviços públicos e pessoal da administração do Distrito Federal, bem como sobre organização judiciária, administrativa e matéria tributária dos Territórios;

V - disponham sobre servidores públicos da União, seu regime jurídico, provimento de cargos públicos, estabilidade e aposentadoria de fun- 
cionários civis, reforma e transferência de militares para a inatividade; ou

$\mathrm{VI}$ - concedam anistia relativa a crimes políticos, ouvido o Conselho de Segurança Nacional.

Parágrafo Único. Não serão admitidas emendas que aumentem a despesa prevista:

a) nos projetos cuja iniciativa seja da exclusiva competência do Presidente da República; ou

b) nos projetos sobre organização dos serviços administrativos da Câmara dos Deputados, do Senado Federal e dos Tribunais Federais".

Paralelamente, foi muito aperfeiçoado e dinamizado o Sistema de Assessoria Legislativa, que, como vimos no diagrama, tem seu Órgão Central no Gabinete Civil da Presidência da República.

2. pronunciamentos no Congresso - este segundo tipo de ação decorria do eco provocado pelos pronunciamentos políticos no Congresso. Este eco, ou repercussão pública, cada dia passa a depender mais do conteúdo técnico-analítico dos pronunciamentos, do que dos seus efeitos imediatos.

3. pressão política - enquanto perdurou o sistema de sustentação política permanente dos cargos executivos, fazia-se necessário o apoio político. № momento em que o Executivo passa a ser analisado pelas suas capacidade técnico-administrativas no cumprimento de suas missões, o País passou a ter estabilidade governamental, a pres. são política passou, também, a ser declinante $\mathrm{s}^{\circ}$. bre o Executivo.

Diante destas modificações, o destaque relativo dos Gabinetes, conseqüência das atividades da "assistência direta $e$ imediata ao Ministro de Estado em sua representação política e social", foi reduzido.

Entretanto, ao mesmo tempo em que ocorriam estes fatos na área política, desenvolviam-se e evoluíam para um nível téc 
nico as atividades governamentais de Relações Públicas. É necessário ressaltar os aspectos técnicos das Relações Públicas, que não se confundem com a "representação social". Neste campo, as diretrizes técnicas emanadas da Assessoria Especial de Relações Públicas são suficientemente claras e objetivas.

Desta forma, as atividades dos Gabinetes dos Ministérios Civis modificam-se sensivelmente, para um nível mais técnico e complexo, ajustando-se ao modelo de administração sistêmica e, em conseqüência, menos personalista.

\section{OS ASSUNTOS QUE CONSTITUEM AS AREAS DE COMPE- TENCIA DOS MINISTÉRIOS CIVIS E AS FUNÇÕES DE RE- LAÇÕES PÚBLICAS}

A fim de melhor conceituar este novo campo de trabalho, de Relações Públicas, e sua importância para a Administração Pública, os assuntos que constituem as áreas de competência dos Ministérios Civis, isto é, as atividades fins, podem ser apresentadas conforme o quadro a seguir. (ver págs. 132 e 133)

O trabalho de Relações Públicas está intimamente relacionado com o desempenho no cumprimento das responsabilidades. Ele se constitui, antes de tudo, na avaliação das opiniões dos diferentes públicos sobre este desempenho. Estas opiniões devem ser classificadas, especialmente as que são desfavoráveis ou críticas, em três grupos:

$1 .^{\circ}$ - procedentes - são aquelas que irão exigir o aprimoramento no cumprimento das responsabilidades;

$2 .^{\circ}$ - as improcedentes, por falta do conhecimento - são aquelas que irão constituir os objetivos da comunicação social, isto é, do plano de relações públicas;

$3 .^{\circ}$ - as improcedentes, por serem orientadas com segundas intenções.

Desta forma, as Relações Públicas podem se constituir em importante função de Assistência aos Ministros de Estado, em primeiro lugar, informando sobre problemas executivos e operacionais e, em segundo lugar, prestando, aos diferentes públicos, informações que possam dirimir dúvidas ou mal entendidos. 


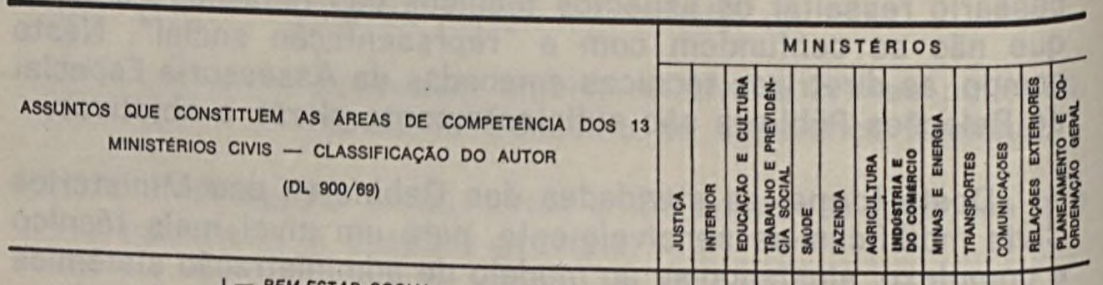

\section{1 - BEM-ESTAR SOCIAL}

\section{A. ORGANIZAÇa SOCIAL E ASSISTENCIA A POPULAÇO}

1. Ordem juridica, nacionalidade, cidadanla, direitos politicos garantias

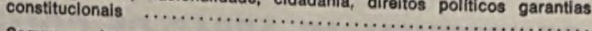

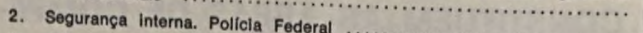

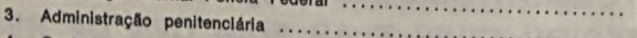

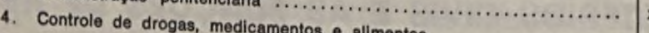

5. Assistencla a populaçø̌es atingides por calimentos ...................

6. Assistencia ao inilomidades públicas

7. Previdencla e Assistencia

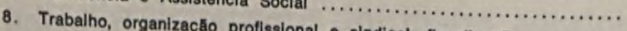

9. Atividades médicas e pindical; fiscallzaçăo ...........

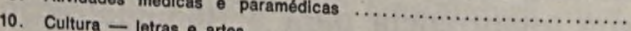

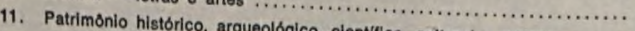

12. Açăo preventiva em geral; vigico, cientifico, cultural e artistico ....... marltimos, fluyiais

\section{B. ORganizaça ESPACIAL dA POPULAÇAO}

1. Radicaçắo de populaçб̃es, ocupaçắo do território - Migraçర̄es internas

2. Politica de imigraçấo

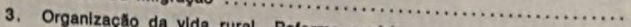

4. Programa da vida rural. Reforma agrária

5. Programa nacional de habitaçăo

5. Saneamento Básico

6. Beneficiamento de

7. Assistencia aos Munielplo proteçăo contra secas e inundaçбes ......

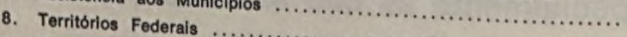

9. Desenvolvimento Reglonal

\section{DESENVOLVIMENTO dOS RECURSOS hUMANOS}

1. Educaçđ̃o; ensino (exceto milltar): magistério

2. Desportos

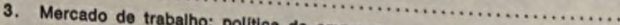

4. Politica naclonal de politica de emprego

5. Politica nacional de saúdo

5. Pesquisas médico sanitárias

\section{II - ECONOMIA}

\section{A. ADMINISTRAÇAO MONETARIA E FISCAL}

1. Assuntos monetarios, crediticios, financeiros e fiscals; poupança popular

2. Estimulos financeiros e crediticios à agropecuária $\ldots \ldots \ldots \ldots \ldots \ldots$.

4. Arrecadaçăo

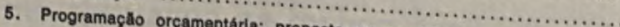

6. Administraçăo financeira proposta orçamentária anual

7. Seguros privados e capitalizaci.

8. Politica Salarial 


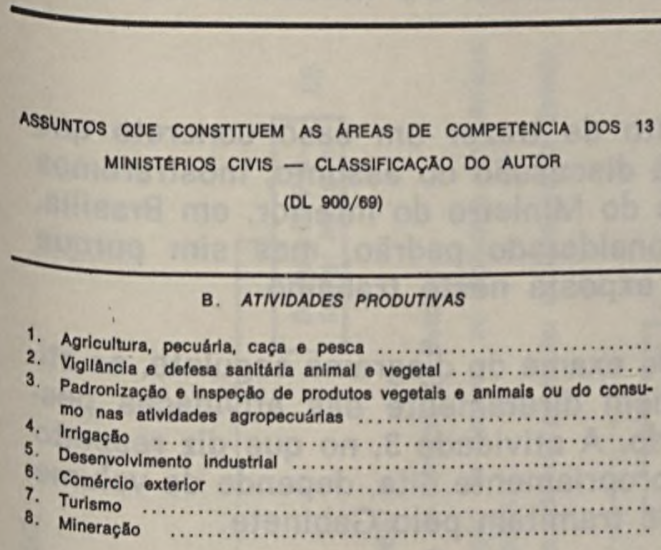

\section{INFRA-ESTRUTURA ECONOMICA}

1. Indústria do petróleo

2. Indústrias de energia elétrice................... Inclusive de natureza nuclear

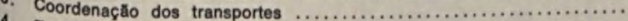

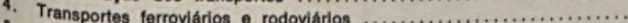

5. Tran€portes aquaviários. Marinha Mercante; portos e vias navegáveis

6. Participaçăo na coordenaçăo dos transportes aeroviários, na forma

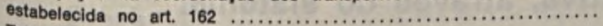

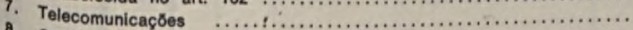

8. Serviços postais

\section{RECURSOS NATURAIS}

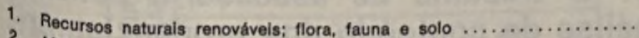

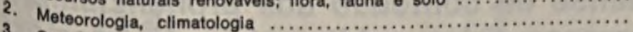

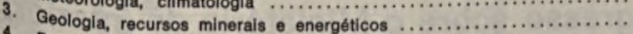

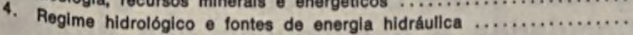

\section{E. PESQUISA APLICADA}

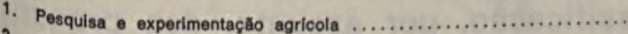

2. Pesquisa e experimentaçắo tecnológica industrial

3. Estudos e pesquisas sócio-econ®micas, inclusive setoriais e reglonais

4. Sistema estatistico e cartografico nacionals

\section{III - RELACOOES EXTERIORES}

1. Politica Internacional

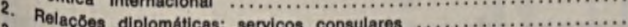

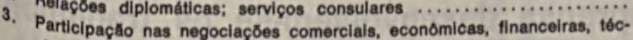
nicas e culturals com paises entidades estrangeiras ...............

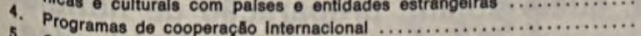

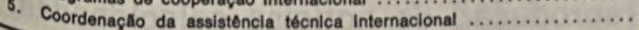

\section{IV - OUTROS ASSUNTOS}

1. Plano Geral do Governo, sua coordenaçấo, Integraçlo dos planos re-

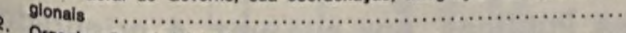

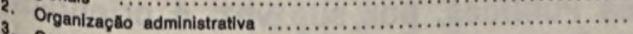

3. Contabilldade administrativa auditoria

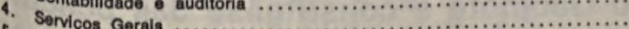

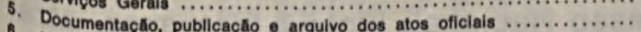

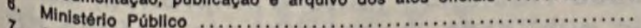

7. Colaboraçăo com o Ministério Públlico Junto à Justiça do Trabalho.....

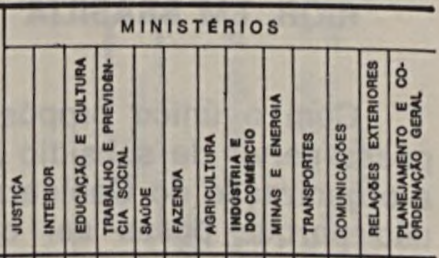

$x$

$x$

$x$ 


\section{A ORGANIZAÇÃO DO GABINETE DO MINISTRO DO INTE- RIOR, EM BRASILIA}

Com o único propósito de trazer um caso concreto que possa servir de subsídio à discussão do assunto, mostraremos a organização do Gabinete do Ministro do Interior, em Brasília, não porque possa ser considerado padrão, mas sim porque segue a orientação geral exposta neste trabalho.

Como se depreende do exame do diagrama seguinte, as atividades de 1 e 2 dependem diretamente das atividades pessoais do Ministro de Estado. A atividade 3, no que diz respeito à Secretaria do Gabinete propriamente dita, depende do volume de documentos oficiais que tramitam pelo Gabinete. trabalhos:

Na Assessoria Parlamentar desenvolvem-se dois tipos de

a) assessoria legislativa, através do sistema;

b) assessoria política, intimamente ligada ao sistema de relações públicas. O trabalho de assessoria política constitui-se na análise de conteúdo dos pronunciamentos feitos no Congresso sobre o Ministério do Interior, e seus Órgãos Vinculados e a execução dos programas que são de sua responsabilidade. Este trabalho de análise e classificação, por assunto, dos pronunciamentos, constitui-se em excelente fonte de pesquisa permanente, indispensável para alimentar e avaliar 0 Plano de Relações. Públicas.

$\mathrm{Na}$ Assessoria de Imprensa desenvolvem-se os trabalhos diários ligados à imprensa, quais sejam, preparação de noticiário, recorte de jornais, reprodução de notícias selecionadas. cobertura jornalistica, contatos com a imprensa etc.

O trabalho de Relações Públicas, por sua vez, é orientado diretamente pela Chefia do Gabinete e constitui-se das pesquisas feitas junto ao Congresso Nacional, junto à Imprensa, atraconteúdo da correspondência particular endereçada ao Ministro de Estado e das observações pessoais diretas. Estas difeR. Serv. Públ., Brasilia, 108 (2): mai./ago. 1973 


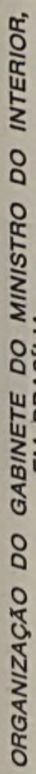

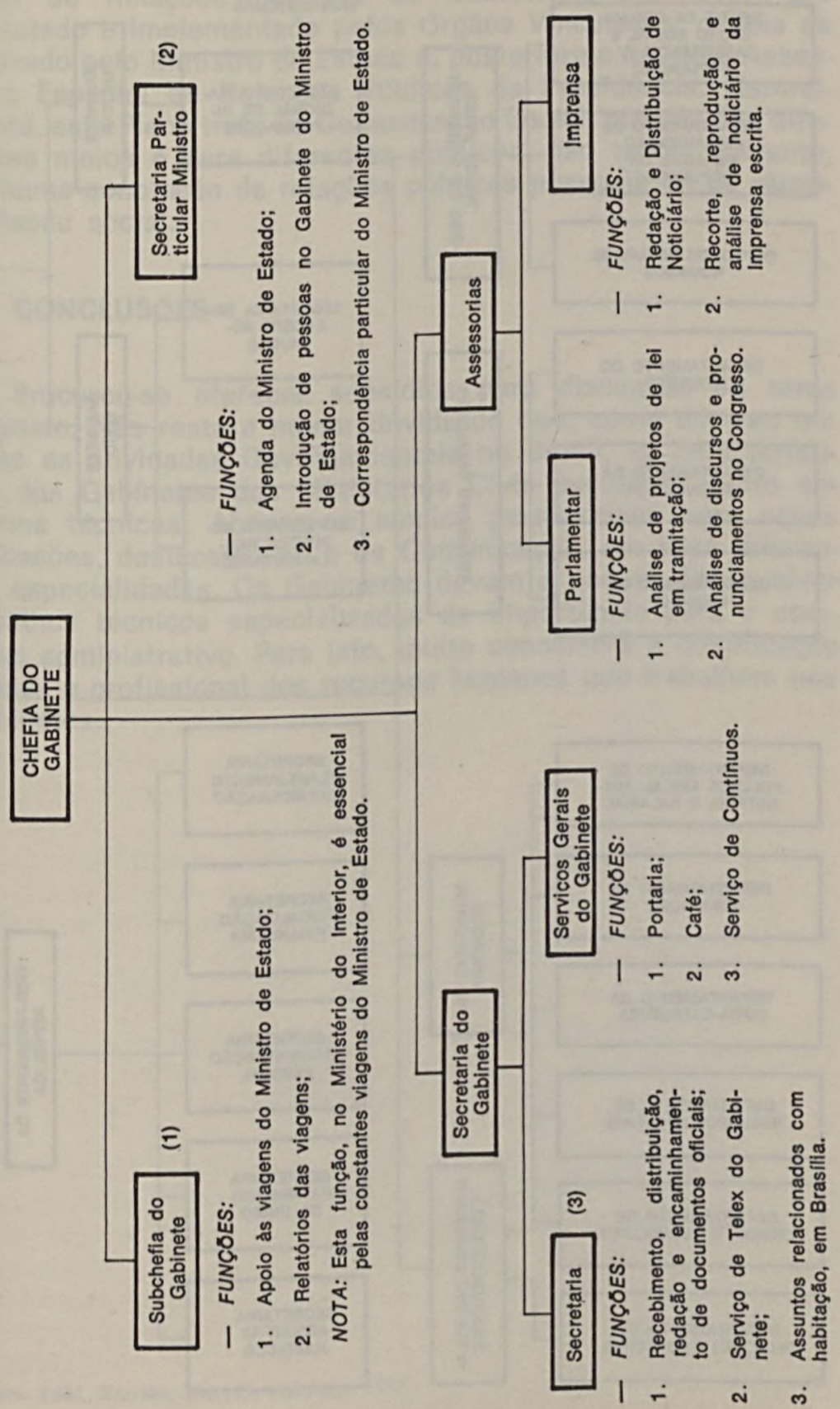


ATIVIDADES FINS

DEPTO. DE ORGANIZAÇÃO SOCIAL E ASSISTENCIA A POPULAÇÃO

\section{DEPARTAMENTO DE}

ORGANIZAÇA

ESPACIAL DA POPULAÇAO
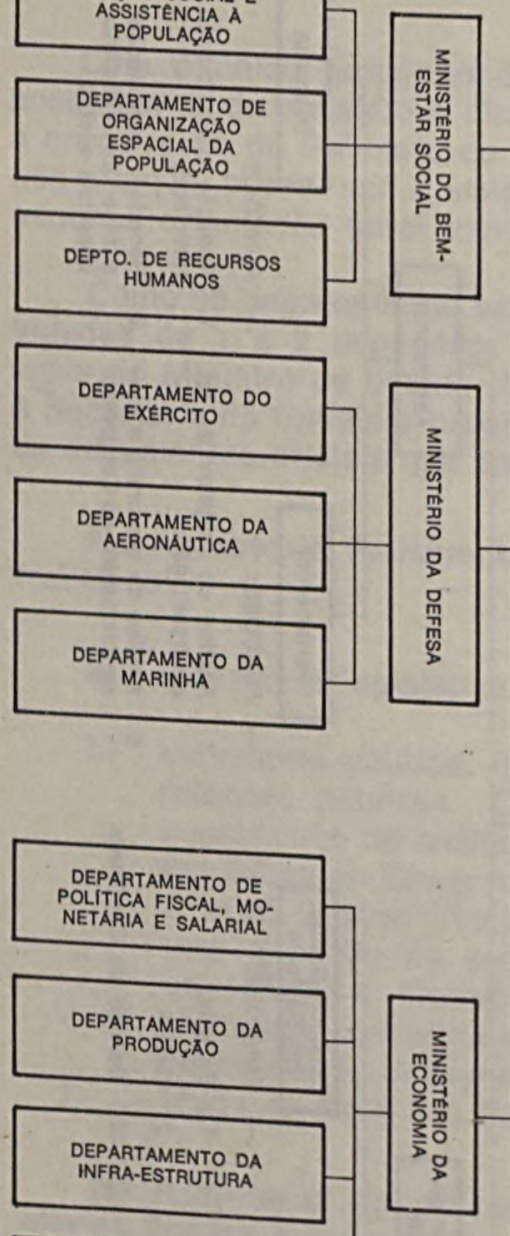

ATIVIDADES MEIO ORGAOS CENTRAIS
DOS SISTEMAS

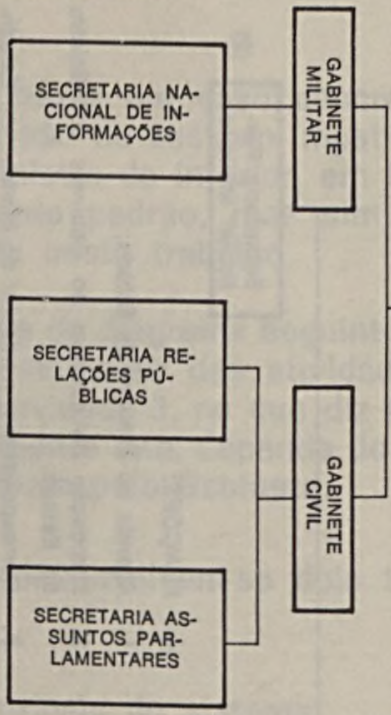

PLANEJAMENTO

COORDENAÇÃO

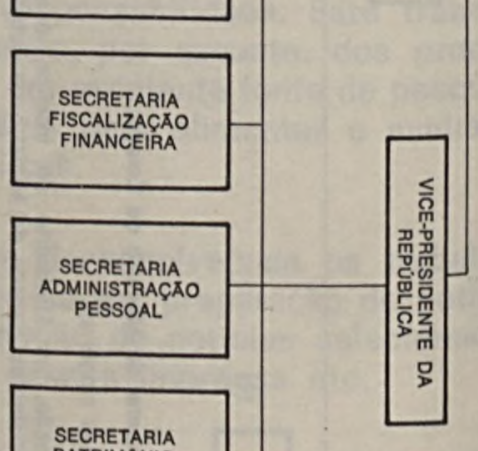

DEPARTAMENTO DE CIENCIA E TECNOLOGIA
PATRIMONIO

DA UNIAO

SECRETARIA

ASSUNTOS

JURIDICOS 
rentes fontes de pesquisa são utilizadas para a preparação do Plano de Relações Públicas do Ministério, que deverá ser executado e implementado pelos Órgãos Vinculados, depois de aprovado pelo Ministro de Estado e, posteriormente, pela Assessoria Especial de Relações Públicas da Presidência. Naturalmente, este Plano trata de Comunicação Social, através dos diferentes meios e para diferentes públicos, não tendo, portanto, nenhuma conotação de relações públicas pessoais ou de representação social.

\section{CONCLUSÕES}

Procurou-se oferecer subsídios para discussão do tema proposto. Não resta a menor dúvida de que, como ocorreu em todas as atividades Governamentais no Brasil, as características dos Gabinetes dos Ministérios Civis evoluíram muito em termos técnicos. Abriram-se amplas perspectivas para novas profissões, destacando-se a de Comunicação, em suas diferentes especialidades. Os Gabinetes devem e podem desenvolver trabalhos técnicos especializados de importância para o complexo administrativo. Para isto, muito concorrerá a qualificação técnica e profissional dos recursos humanos que trabalham nos Gabinetes. 


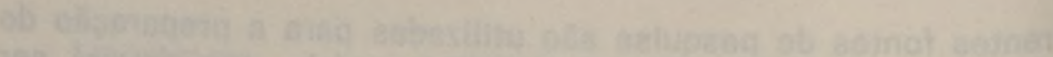

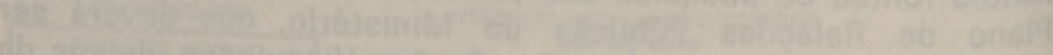

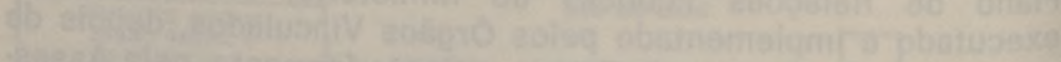

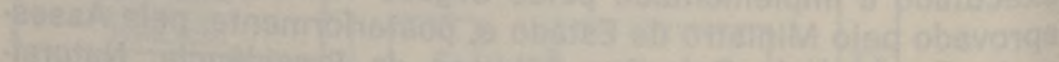

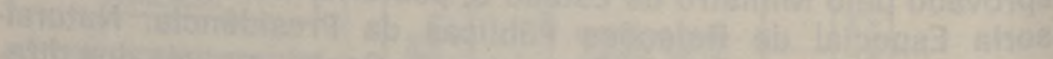

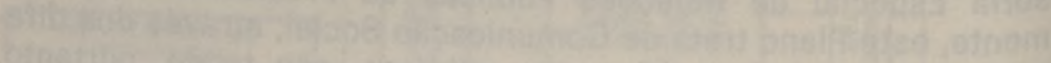

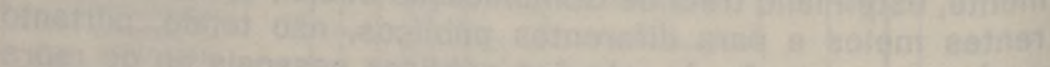

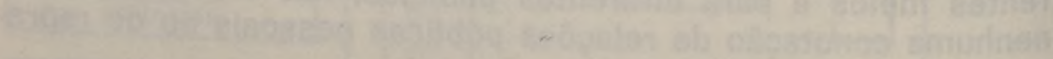

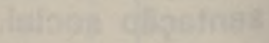

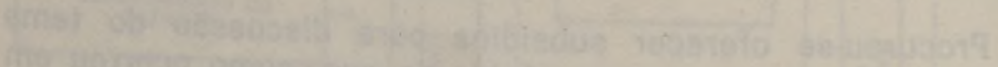

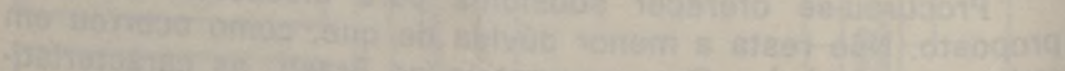

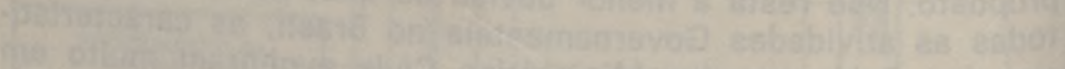

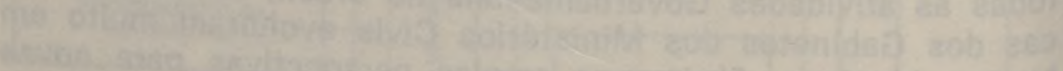

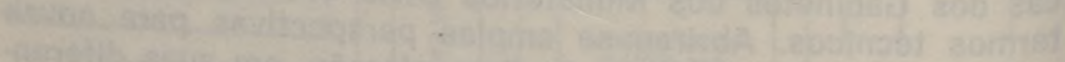
Whatin.

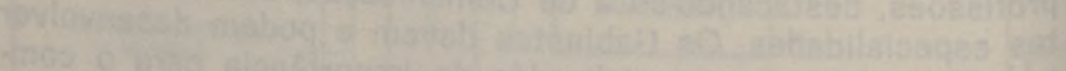

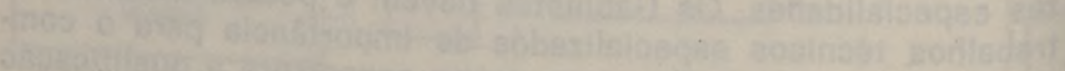

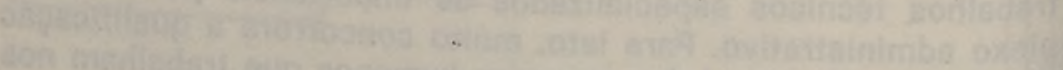

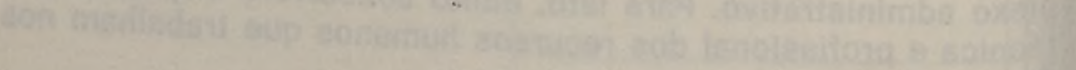

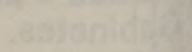
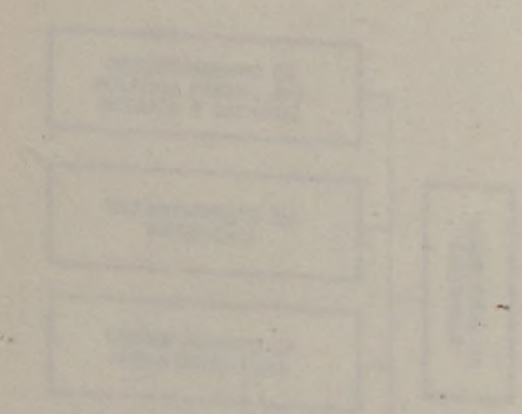